\title{
Thinking With Contemporary Art: Re Envisioning Material Movements in Early Childhood Spaces
}

\author{
Adrienne Argent
}

Adrienne Argent is an early childhood educator residing in Vancouver, British Columbia. She is a master's student in early childhood education at the University of British Columbia. Email: aargent@capilanou.ca

This article focuses on the unfolding processes and surprising openings that are revealed through engaging with themes produced by contemporary art in early childhood settings. Rather than contemplating objects of art as finished pieces with inherent meanings, this article shows how materials and themes are in a constant state of becoming. Central to the article is the work of Korean artist Kimsooja and the themes generated through her recent exhibit, Unfolding. The author presents a series of reflections about the transformative effect of this artist's work in clearing away the author's previously held understandings of how thinking through the work of contemporary artists is done in early childhood spaces.

Keywords: early childhood education; contemporary art; materiality, Kimsooja; entanglements; embodiment

\section{Thinking Through the Constructs of an Artist}

I work as an early childhood educator with children aged 18 to 29 months in a campus childcare centre in British Columbia. Visiting art galleries is something I enjoy doing, and, along with my colleagues and our centre's atelierista, often plan a gallery visit as a professional development excursion. When I visit an art exhibit, I am careful not to engage with the artist's work in a way that suggests that children can also make or do similar creations. I avoid making statements like "We can do this with the children" or "Let's set up the classroom in this way." Rather, I believe much can be gained by engaging with the overarching themes proposed by the artist and considering how these themes might challenge us to view the culture of our children's spaces differently. I notice how various media, such as video installations, are used in galleries to invoke multiple perspectives that may produce surprising embodied reactions. There are many things to pay attention to when visiting a gallery. I find the curation process particularly fascinating. The organization of the space can allow for dialogue to take place between the viewer and the art. The placement of objects and text will not only guide but encourage pauses and places of obstruction, where the viewer is inspired to engage in a certain way.

In a recent visit to the Vancouver Art Gallery I encountered the artwork of Kimsooja, a South Korean conceptual artist. This visit represented a metaphorical act of excavation. It shaped and shifted the landscape of my thinking and cleared away old "truths" I had previously held, allowing me to experience and make sense of children's spaces in new and surprising ways. This process at times felt powerful, like a machine breaking ground and dramatically altering the earth's terrain. Yet, at other times, it felt like a gentle brushing aside, as an archaeologist filters through soil in search of artifacts. This sense of smashing, filtering, and sifting cleared out practices and frameworks that have previously prevailed, provoking a way to unlearn pedagogical assumptions and beliefs. This transformative act of unearthing revealed new emotions and movements and unfolded ways of seeing and experiencing the vibrant life within a children's space.

In this paper I reflect on my previously held notions of thinking with an artist. I then discuss what it means to be to be ruptured or changed by art and how these ruptures present themselves in the practice of being an educator. Woven throughout are examples from Kimsooja's exhibit Unfolding (Vancouver Art Gallery, October 2013), with my reflections on how her themes helped to transform our curriculum engagements alongside children.

\section{Clearing Out Previously Held Notions}

I have always felt that bringing the work of contemporary artists to early childhood settings is a problematic terrain to 
navigate. While I understand the value of responding to children's aesthetic awareness, and the importance of bringing complexity to their ideas and creative processes, I am cautious about attempting to replicate contemporary art with children, such as giving technical instruction leading to the production of art. My uneasiness with this process stems from the rigid constraints placed on children's creative intentions and the containment of possibilities that materials can perpetuate. Materials are powerful forces that suggest, provoke, and produce both subtle and dynamic flows, and transformations and relationships between other materials, objects, and humans. This process cannot be easily understood as predictable or outcome oriented. Educators have long been instructed to simply expose children to fine art and beautiful things. For example, Feeney and Moravcik (1987) propose that "for aesthetic development to occur children need experience with beautiful environments within the school and outside of it, exposure to fine art, and opportunities to discuss art and beauty with thoughtful adults" (p. 11). These notions of supporting aesthetic development in early childhood programs are well intentioned; however, I believe they limit the agency of the child and propose a very flattened out understanding of how artistic processes can be experienced. I feel educators can find themselves in a very precarious place when the arts become an orderly form of curriculum, producing idealized examples of art making. Who decides what has aesthetic value in an early childhood environment? What is overlooked in the process of replicating? Kind (2010) cautions that "in many ways educators limit this richness or provoke a narrowing of experience by what we think, what we expect, and the frames we use to interpret children's artistic intentions" (p. 116). Echoing Kind, I wonder if educators can look beyond the notion of exposure to beauty toward a more embodied response to aesthetics. Could this engagement be reenvisioned to being in dialogue with the lively qualities of space, light, materials, and objects?

Thinking through the constructs of contemporary art can involve taking on many meanings beyond reproducing art objects or images, building technical skills, or simply receiving meaning. Contemporary art can churn up new meaning and trouble our perceptions of how curriculum is created and lived. As an educator, I have been provoked to think differently and to feel the world in alternate ways. I have become aware through critical reflection that art, with its own sense of agency, does something to and with the viewer/educator.

I returned to Kimsooja's exhibit several times, sometimes with my atelierista and colleagues and other times by myself. I found I was compelled to write and sketch my reflections and embodied reactions on paper, always revisiting and uncovering new meaning. Harrist and Richardson (2012) describe a similar process through Emmanuel Levinas's theory of ethics of an encounter:

Each voice incorporates its own evaluative position at the same time that it remains open to the potential truth of the Other... This back and forth process draws out the potential insight and wisdom of different voices or positions and allows a new, temporary, open-ended unity to emerge. (p. 350)

This dialogue with the "Other"/Kimsooja lingers in my memory, and as time passes she still compels me to think in certain ways about material engagements with children and educators.

\section{Kimsooja: Unfolding}

Kimsooja is a Korean-born artist and her exhibit Unfolding was a retrospective compilation of 30 years of her work. The exhibit centred on her use of fabric and the act of sewing as metaphors for the human experience. In an interview, Kimsooja described her relationship to cloth and the act of sewing:

In the midst of a common act of sewing blankets with my mother, I had a clandestine and surprising experience in which all of my senses, thoughts and activities all coincided with one another. In this experience, I discovered the possibility that so many memories, pains and affections of life buried unnoticed so far could be connoted in it. I was totally fascinated by the lines of longitude and latitude as the basic structure of cloth; its primordial colour, the feeling of identity between the cloth and me while it was being sewn; and the curious nostalgia evoked by those things. (Kim, 2001, para. 7) 
Kimsooja's vivid description speaks to a very embodied comprehension of cloth. This intimate comprehension enmeshes the presence of history, emotion, memory/time and suggests that the movement of hand-needle-thread-cloth could invoke a back and forth passage through time. As I walked through the gallery, I was continually confronted by the gestures of wrapping, bundling, and folding of personal possessions and everyday objects in layers of fabric. Soft, plump bundles of fabric called bottari were placed like small obstacles across the gallery floor. I meandered around them, pausing to admire the beauty and organic shapes, but also to consider the meaning and significance of wrapping. Bottari holds significant meaning and purpose in Korean culture. Bottari is a form of handmade luggage usually made from a bedsheet of brightly coloured cloth with embroidery stitched into it. It is used to transport food and personal belongings.

Embodiment is a commanding voice throughout the Unfolding exhibit. As I wandered through the brightly coloured traditional Korean fabric, I too became enfolded and stitched into the artist's themes and visuals.

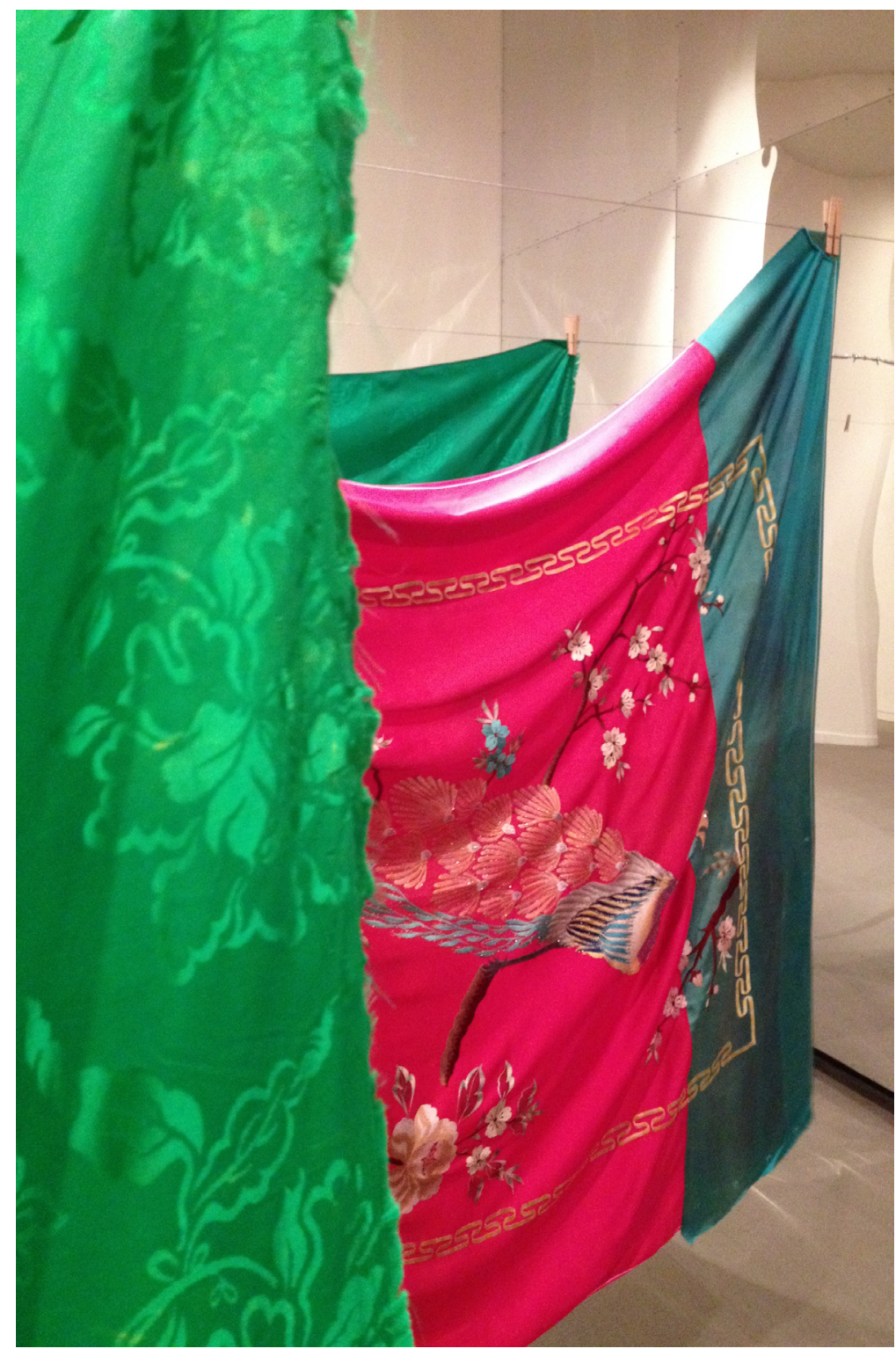

Figure 1. Textile panels from Kimsooja's Unfolding exhibit, Vancouver Art Gallery. Photo by author. 
Many of Kimsooja's installations are steeped in notions of time, as described by Selene Wendt in the exhibition catalogue (Vancouver Art Gallery \& Cantz, 2014): "Reflections about life and art are spun from a seemingly endless thread that weaves in and out of time and space where past, present and future are melded into one" (p. 58). Contemporary art challenges the viewer to be present and to engage with time. All creative output is an expenditure of time, whether that be the viewer's experience unfolding through time, the time it took for the artist to create the piece, and the historical time period in which it was created. This theme is an example that speaks to me of the many layers and nuances to be observed when engaging with the constructs of an artist. The work of an artist cannot be received as a static subject; rather, it is wrought with elements of time and flux. As I wandered through Kimsooja's exhibit, I surrendered to her themes, colours, and patterns. I encircled, paused, and gazed and felt myself become porous as her installations provoked and began to work on me in surprising ways. Each time I visited the Unfolding exhibit, I was compelled to write reflect, interpret, and reinterpret my wonderings and affectations. Many of these scattered bits and pieces of reflection have in many ways become threads of meanings and questions that have stitched themselves into my very being - and now, also, into this article.

As I gaze down at the bottari, I start to ponder the very cloth I am wearing on this day, the dark denim that wraps my legs, the wool jacket that encloses my upper torso, and the cloth bag slung over my shoulder holding my personal things, money, identification, and so on. These pieces of cloth travel with me as I move through life, but even before they came to me they were assembled somewhere else, travelled from unknown places in unknown ways, and passed through several strangers' hands. Now these cloths are mine. I start to think about all the meanings that are embedded within cloth. Symbols, images, colours, and textures come to represent choices, limitations, status, ethnicity, popular culture, and so on and so forth. Coming into contact with cloth entangles us into something much larger. I begin to consider the mass production of cloth for multinational corporations and the burdens of globalization that become stained and stitched into the creation of our garments. This global interconnectivity entangles me to a past, present, and a future that is driven by capitalism. I question: How is Kimsooja's cloth different? Her cloth is not marked by a logo or a tag that reads "Made in Korea." Kimsooja's cloth is woven with threads of politics that are of a much more personal and intimate nature. As such, her cloth becomes an intricate intersection of threads that represent identity, culture, the joys and suffering of human existence, and the passages of time. I pause again to reflect on my own clothing and I realize that as our human bodies travel and move, our clothes encapsulate so much. They become vessels that contain emotional states, growth, and bodily change. Essentially, they bundle up the pain and pleasures of human existence.

Engaging with the constructs of contemporary art has immeasurable value to early childhood education. It can be understood as a practice that enlivens critical thinking and bolsters the flexibility needed to reconceptualize ways of knowing that are embodied, relational, and multidimensional. It is an ethical practice that helps to create a detour from the pervasive notions of consensus and fixed notions of how life in children's spaces is lived. It challenges educators to relocate childhood into a world that is much bigger than us, and where forces such as time, space, matter, and meaning form a complex web of existence with no fixed boundaries.

Throughout Kimsooja's exhibit there were repetitious acts of washing, hanging, and placing fabric. These movements become rhythmic expressions and poetic dances disguised within the mundane acts of daily life. Throughout her installations and video performances, the artist challenges the inorganic divide between art and everyday existence. Kimsooja's "Deductive Objects" series highlights the use of ready-made objects such as farming tools, chairs, and window frames, and she wraps them with brightly coloured Korean bedcloths. Her work has an in-progress feel to it. The loosely tied knots and untrimmed threads echo an intimate sense of longing and remembrance of a human or a place somewhere in the past. I wanted to reach out and gently slide my fingers between the layers to loosen and tease out the stories and secrets that were wrapped between the layers and folds of fabric covering these unassuming objects. In these moments I began to feel drawn into the suggestive in-between spaces of matter, material, time, and place. The "Deductive Objects" installation emoted an essence that transformed these mundane and banal objects into highly expressive vessels of life that were imbued with emotion and memory. Engaging with her work was not a passive experience: It struck hard and created many fissures and openings in my understanding of thinking with an artist. In the many months that have passed, I have continually returned to Kimsooja's work and themes. She haunts me in the most beautiful ways. I'm quite certain that Kimsooja is acknowledging the "fabric of 
society": her work conveys a strong sense of compassion for the human condition. These delicate threads that intersect and form tension eventually become fabric, and each thread contributes to something greater. Symbolically, each thread could be understood as an individual contributing within society. Reflecting on these ideas, I began to reimagine my classroom and the complex networks and entanglements of gestures, language, images, objects, and reverberations that exist. I questioned: What meaning do the threads hold? Am I acknowledging these forces as important components of the collective lived experience of a busy classroom?

\section{Matter and Material Entanglements}

In my childcare program, Scholastic book catalogues arrive every month in large stacks. As they are distributed, they decorate the cubby doors of all the children. Many childcare programs make these common, brightly coloured newsprint publications available to the families. For me, these all-too-common objects have become unattractive and distracting as they clutter up our space. However, children think very differently. These papers mean something to children and they hold great value. I've known this for some time now; however, it wasn't until I engaged with the constructs of Kimsooja that I began to dig below the landscape of the childcare program to understand this value in a clearer sense. Guided by the resonance of the "Deductive Objects" series, I began to observe and understand these seemingly benign papers differently, and their presence in our space took up new meaning and possibility.

These papers - they live in our space. Small hands clutch the edges and they are tucked safely, with importance, under armpits. Children travel with these objects and they become extensions of their bodies. Pointing, gazing at, crinkling, folding, layering, dipping, or tearing these materials summons up moments of embodied knowing that can appear peculiar to the adults who sit slightly on the outskirts of these rituals. The images of Hello Kitty and Thomas the Tank Engine accompany children as their dailiness unfolds. What do these papers reflect to the children? Their small hands become well acquainted with texture and the grain of the paper. Fingers produce tears. Thin, delicate, and curled, these torn bits flutter and come to rest on the cool surface of clay, onto the slipperiness of Scola Cel, into wooden bowls and tucked into the folds of our clothing and caught up in our hair. Colours, texts, and iconic images become fragmented, changed, yet still recognizable as they become embedded into objects, the environment, and our bodies. 


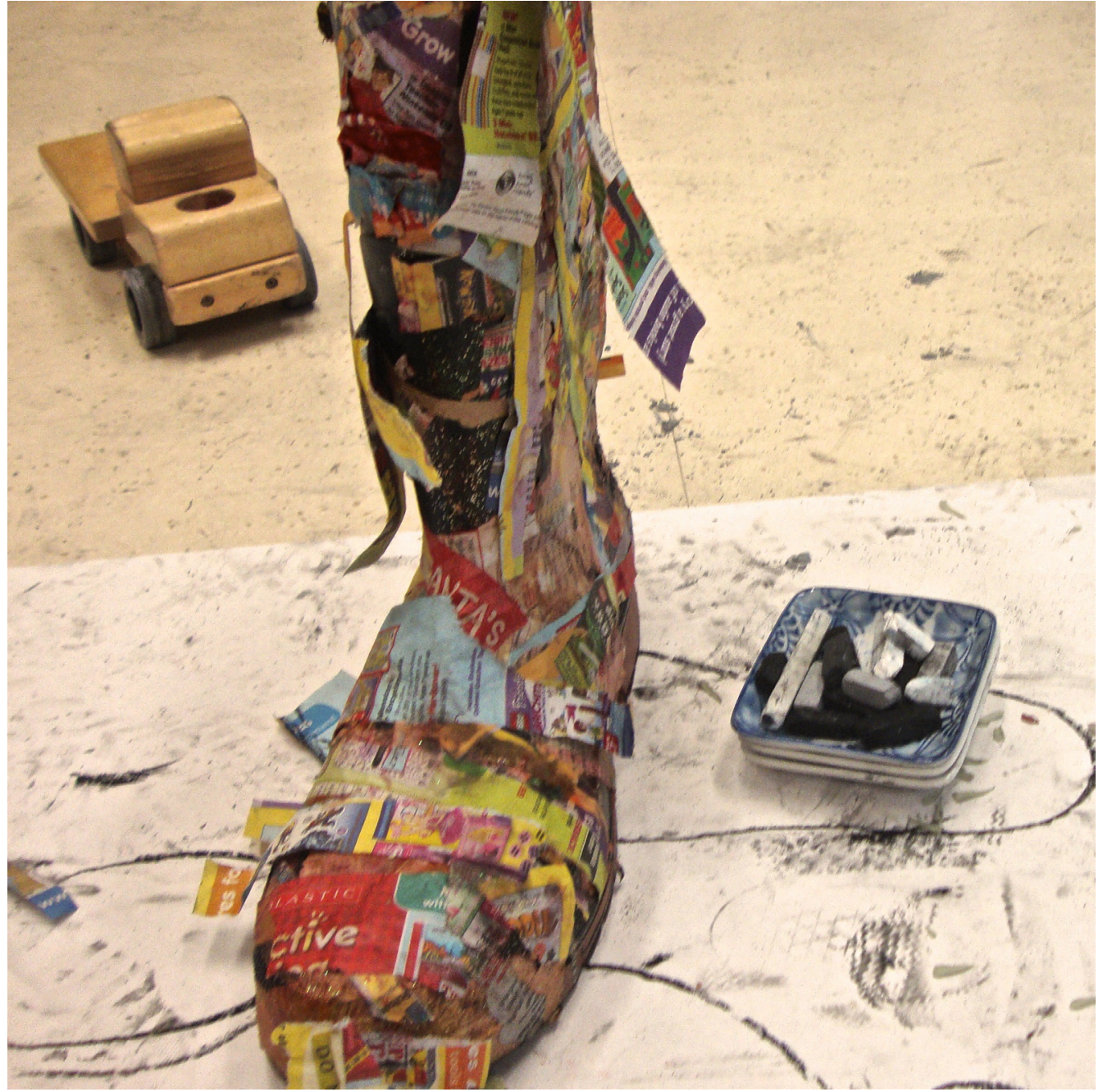

Figure 2. Boot wrapped in layers of paper for collaborative art project. Photo by author.

The papers are in flux as they are torn into pieces and flutter and disperse around the room. Ingold (2007) helps me to sift further through this generative flux of materials:

Far from the being of inanimate stuff typically envisioned by modern thought, materials in this original sense are the active constituents of a world-in-formation. Wherever life is going on, they are restlessly on the move-flowing, scraping, mixing and mutating. (p. 11)

Ingold's notion of the world-in-formation draws me in. I begin to become sensitively attuned to the currents of movement and constant travelling of paper and bodies. These movements echo Kimsooja's repetitive gestures of washing, folding, and wrapping fabric, guiding me deeper in my observations and my own partaking of the entanglement of children, materials, and movement in my classroom. Kimsooja brought beauty and expressiveness to everyday household rituals involving cloth. In a similar way, repetitions of placing/unplacing, wrapping/unwrapping, folding/unfolding are common occurrences and rhythms in my classroom. I begin to notice these gestures in the many ways our bodies move and play with the materials circulating and flowing throughout our space. The following description is a vignette from our classroom:

Fatima's hands and arms are caked in a mixture of Scola Cel and clay, enveloping her dark brown skin with grey earthy 
tones. The surface of her skin tells a story of time as some parts are wet and fresh with the drippiness of the materials and other parts are dry and cracked. She sits amid several bowls of torn paper pieces. Each shred holds patterns, familiar text, and slivers of images. She is selective, closely examining each torn piece. Today, any portion of Dora the Explorer or Pete the Cat is especially desirable. Only moments earlier, she sat before a large block of clay, her nimble fingers layering strips of paper across the surface of the clay, forming a grid-like pattern. She plucks at the edges and gently peels them back. Shifting to face her teacher, she begins to lay them down on the skin of her wrist and forearm. She glances up and the teacher smiles permission. There is a seamless flow to the movements of her hands as they move from bowl to bowl, endlessly searching for the right fragment of paper, dipping it in Scola Cel and smoothing the paper across her skin. This process repeats over and over. Her face is calm and focused, and she is silent. Her fingers are expressive, communicating a deep understanding of the materials at play here. She lovingly wraps her teacher's arm. Pausing, her hands and wrists make fluid circular motions as she smoothes out the surface of these thin bits of paper and molds them to the contours of her teacher's wrist and arm. Tearing, dipping, peeling, wrapping, smoothing - the process repeats.

This event of tearing and placing/unplacing paper becomes a repetitious act, a ritual that in many ways unites children and adults together. A material that once seemed so banal has been caught up in a current of transformation, eliciting performance-like qualities. Kimsooja's work presented new ways of engaging with everyday relations to fabric through transporting and handling it, ways that revealed expressive beauty and a deep sense of interconnectedness with the world. In our classroom, reflecting on Kimsooja's themes, I become attuned to a network of forces at play. I also become aware that I, too, am a part of this network of forces. As I become a part of it, I am also being acted on by other forces, both human and nonhuman. Kind (2014) explains how Deleuze described this intersection of forces:

In this regard, Gilles Deleuze helps us to see encounters of materials, objects, places, and humans as part of the flow of experience. In his view, we are never separate from the world; we are made up of relations; thought creates itself through encounters. (p. 870)

This intricate network can be described as an assemblage of paper-images-children-objects-history-language-time-space. These forces merge and shift, and in the in-between spaces consequences are produced. I become caught up and folded into these material encounters, continuing to document and revisit my understandings through writing, dialogue with others, photography, video, and fragments of artistic renderings. My journey with Kimsooja continues.

I stand back to observe. I examine photos and video clips, noticing that the movements and gestures of tearing, placing/ unplacing, wrapping/unwrapping have a continuous flow and rhythm, motions that are sweeping and grand, but also sometimes finite and delicate. There is beauty in this process: This beauty exists in the movement of the papers, but also in how the paper dances with the children. There is a mutual interdependence. What prompts Fatima to move her hands so expressively? Is it the layered experience of materials meeting, rubbing up against each other, and merging together? The movements of layering and smoothing onto the texture of skin? The powerful impact of continuous flow and repetition? This powerful network of forces produces relationships between material and matter, and this idea of being in-formation becomes a process I not only witness but experience in its unfolding. I am unearthing a new understanding of beauty, moving beyond beauty in form to beauty in process. Springgay (2008) discusses Kennedy's (2004) idea of the "aesthetic of sensation":

An aesthetics of sensation is not based on "normalcy" or structuralist semiotics, but an aesthetics that vibrates and reverberates in modulation with, in, and through bodied encounters, shifting such concepts as "beauty" from form to process - an assemblage. (para. 5)

Ideas such as the aesthetics of sensation were once concealed from me, enshrouded in the debris of fixed notions and assumptions regarding children's spaces. Kimsooja has invited me to see and experience that the human body does not function in an autonomous manner within the environment; rather, it is in a constant process of entwining and interacting with matter. Akin to Kimsooja's fabric that wrapped the everyday personal objects, it is in the in-between spaces where matter and material meet that movements, expressions, and meanings are produced through the processes of touch, time, and history. This process has uprooted sensitivity to the objects children nominate as meaningful. An excavation project has 
been set into motion as the once familiar topography of the Dogwood Room children's space is reformed, creating space for new knowledge to reveal itself.

\section{Conclusion}

A considerable amount of time has passed since I first encountered Kimsooja's exhibit Unfolding. Her themes, however, are still echoing within me. As new rhythms emerge in my classroom and different materials take hold in new and surprising ways, the exhibit Unfolding still guides me and resonates within me. Her presence haunts in a beautiful, generative way, always producing new configurations of thought and emotions in my engagements with the ever-changing landscape of my toddler classroom. This process of uncovering created a new field of vision and a greater sense of depth of understanding as to what children might possibly be doing. This process forced me to traverse beyond the familiar, encouraging me to look between subjects and acknowledge the beauty and dance of ritual and the shaping and shifting that occurs when materials, humans, objects, and time become entwined. The influence of Kimsooja's work has cut through my old beliefs and assumptions, creating a clearing from which I can become more attuned to the in-between spaces of materials, movement, and bodies.

\section{References}

Feeney, S., \& Moravcik, E. (1987). A thing of beauty: Aesthetic development in young children. Young Children, 42(6), $7-15$.

Harrist, S., \& Richardson, F. C. (2012). Levinas and hermeneutics on ethics and the other. Theory \& Psychology, 22(3), 342-358. doi: 10.1177/0959354310389647

Ingold, T. (2007). Materials against materiality. Archaeological Dialogues, 14(1), 1-16. doi: 10.1017/S1380203807002127

Kim, S. J. (2001). Kim Sooja's bottari and her journey. In J. Jefferies (Ed.), Reinventing textiles: Gender and identity (pp. 131-142). Winchester, England: Telos Art Publishing. Retrieved from: http://www.kimsooja.com/texts/sunjung kim_2001.html

Kind, S. (2010). Art encounters: Movements in the visual arts and early childhood education. In V. Pacini-Ketchabaw (Ed.), Flows, rhythms, and intensities of early childhood education curriculum (pp. 113-131). New York, NY: Peter Lang.

Kind, S. (2014). Material encounters. International Journal of Child, Youth, and Family Studies, 5(4.2), 865-877.

Pacini-Ketchabaw, V. (2010). Flows, rhythms, and intensities of early childhood education curriculum. New York, New York: Peter Lang.

Springgay, S. (2008). An ethics of embodiment, civic engagement and a/r/tography: Ways of becoming nomadic in art, research and teaching. Educational Insights, 12(2). Retrieved from: http://einsights.ogpr.educ.ubc.ca/v12n02/ articles/springgay/index.html

Vancouver Art Gallery \& Cantz, H. (2014). Kimsooja unfolding. Exhibition catalogue. Exhibition at Vancouver Art Gallery, October 11-January 26, 2014. 